\title{
Para além de Medusa - retomar a história no palco
}

O trabalho em teatro da austríaca Elfridine Jelinek é conhecido por sua crítica da mitologia. No seu recente 'work in progress', que segue de perto os relatos da mídia sobre a Guerra do Iraque e as torturas em Abu Ghraib, Jelinek concentra-se no efeito mitologizante do 'wartainment'1 que uma população supostamente alerta e educada pode testemunhar como pouco mais que um espetacular melodrama de televisão. De acordo com Jelinek isso rapidamente apaga o evento da memória pública. No segundo passo de seu trabalho em andamento, Babel (2005), ele descontrói essas estratégias telemáticas do esquecimento, ignorância e cegueira das experiências traumáticas pela criação do que ela, de uma forma ligeiramente irônica, chama de 'obra de arte de moralidade'. Jelinek está advogando com seu trabalho por um conceito de história performática (no palco) que inscreve o que não se deixa inscrever: a contingência de eventos de terror, guerra e tortura que rompe continuidade e significação.

Todos nós conhecemos - queiramos ou não - aquelas fotos de tortura, humiIhação, desumanização e abuso sexual que foram tiradas em Abu Ghraib e Guatânamo. Lembramos a fotografia de um homem com um capuz preto sobre a cabeça, em pé sobre uma caixa, seus braços posicionados na forma de cruz, com cabos elétricos conectados em suas mãos. Nós lembramos a pirâmide de homens nus, empilhados em cima uns dos outros nas mais degradantes posições, e talvez nos lembremos de fotos ainda mais horríveis - fotos que andaram ao redor do mundo, acessíveis a todos com uma conexão de internet ou, pelo menos, uma televisão, fotos que podem ser salvas em um servidor, a completamente automática memória do computador.

\footnotetext{
1 Nota do Tradutor: Em 'wartainment' a autora estabelece uma relação entre as palavras 'war' (guerra) e 'entertainment' (entertenimento), para chegar ao neologismo proposto. A ideia que cabe é da exploração com fins de entertenimento das imagens da guerra.
} 
Essas fotos performam o trauma? De fato, pode-se dizer que elas literalmente colocam as pessoas em situações que vão além dos limites do que elas podem psiquicamente aguentar, destruindo suas integridades. Nesse sentido, elas contam com uma definição bem comum de trauma partindo de uma suposição de que as pessoas experienciam choques traumáticos quando elas são forçadas, ou por catástrofes ou por violência física, a situações nas quais elas estão impotentes ${ }^{2}$. Mas o que acontece conosco, os espectadores, as testemunhas de imagens que encenam tais situações? Nós assistimos, talvez fiquemos chocados, talvez nós reajamos com indignação moral, mas, na verdade, essas fotos estão consignadas à insignificância histórica, ao olvido mesmo. É a abundância, ou ainda mais, a serialização das performances pictóricas de momentos traumáticos nos meios eletrônicos que geram um esquecimento do impacto histórico e psicológico precisos. Ainda mais, o de longe demasiado, o excedente é produzido pelo e produz o consumo Como Siegfried Schmidt diz: "As torrentes de imagens no meio audiovisual dificilmente estabelecem reivindicações à lembrança ativa. A comunicação comercializada implica uma política da memória que se baseia mais na serialização do intenso esquecimento que na lembrança avaliativa"3

Com esse artigo eu quero defender a proposição de que a performance do trauma não pode ser discutida, comentada ou lembrada hoje sem levar em conta o discurso e política da mídia pública; especificamente no que diz respeito aos potenciais da mídia eletrônica na distribuição e disseminação de informação. Eu defendo, com Aleida Assman, que não se isole a discussão sobre trauma e memória à questão de sua representatividade. De acordo com ela, tem-se que levar em conta que "a forma e qualidade dos espaços culturais de lembrança são condicionados [...] tanto por interesses sociais e políticos como pelas transformações nos meios técnicos."4

\footnotetext{
2 Veja Judith Hermanm, Die Narben der Gewalt, Paberbon: Junfermannsche Verlagsbuchhandling, 1993, 53: "Trauma psicológico é o sofrimento do fraco. O trauma surge no momento em que a vitima em relação a este poder supremo está desamparada. Este poder é uma autoridade natural, algo catastrófico. Outros fazem prática deste poder, que se trata de crimes violentos. Lembranças traumáticas eliminam a rede social, a qual dá aos homens comuns o sentimento de controle, adesão a um sistema de relacionamento e sentido"

${ }^{3}$ Siegfried J. Schmidt, Die Welten der Medien. Grundlagen und Perspektiven der Medienbeobachtung, Wiesbaden: Vieweg Verlagsgesellschaft, 2003, 68; Aleida Assman, Erinnerungsräume. Formen und Wandlungen des kulturellen Gedächtnisses, München: Beck, 2003, 412: "Os videos em cascata das midias audiovisuais pouco (ainda) elevam a busca a uma lembrança efetiva. Isto pertence a memória política da comunicação comercial, tal que os quadros são postos sobre o intensivo esquecimento da seriedade, mas não postas como lembranças avaliadas."

4 "A forma e qualidade da área das lembranças culturais [...] são também políticas de interesse social assim como das mudanças das técnicas de midia." (Assman, Erinneurungsräume, ver nota 3, 408)
} 
Se nós perguntarmos como o teatro lida com o problema dos eventos traumáticos e suas possibilidades de representação - nós temos que fazê-lo de uma dupla maneira: primeiro, questionar a adequação dos meios representacionais da arte propriamente dita para apresentar ou performar o traumático; e segundo, inquirir se e o quanto a arte (e o teatro em particular) ainda proporciona meios ou formas de representação que sejam capazes de comentar sobre, e fornecer uma alternativa para o "de longe demasiado," o excedente de eventos traumáticos que são performados pelos meios públicos de informação.

Para responder a essas questões eu argumentarei com Jacques Rancière que não temos que considerar somente a troca entre imagens de arte e o mercado de produções de imagens sociais, mas considerar também os diferentes tipos de performances de imagens nos meios de informação, por um lado, e nas artes, por outro. Lidamos aqui com, pelo menos, dois diferentes tipos de imagens. Primeiro, há imagens que tendem a produzir um efeito de equivalência. ${ }^{5}$ Elas substituem o original com uma cópia, fortemente semelhante ao original. Este é o caso de imagens reproduzidas eletronicamente ou tecnicamente, tais como fotografias ou imagens televisivas. Segundo, imagens podem criar uma modificação de similaridade no sentido de que elas performam "um jogo de operações que nós chamamos arte"6 O último implica duas coisas que são relevantes para a arte do teatro. Primeiro, as imagens no teatro produzem dessemelhanças por causa de seu específico aspecto baseado no tempo. O seu carácter ao vivo processa imagens no instante; as imagens acontecem no momento de sua constituição ou performance. Segundo, as imagens no teatro não são

\footnotetext{
${ }^{5}$ Essa noção é usada no sentido do alemão "Ähnlichkeit" que foi o termo central na teoria estética a partir dos gregos. Ela descreve o mais alto nível de exatidão da mimesis, reduplicação da realidade ou a cópia do original. Eu me pergunto. "Ähnlichkeit" dificilmente significa "o mais alto nível de exatidão". Seguindo Rancière não é realmente necessário que a imagem seja absolutamente exata, mas tem que ter o status para tomar o lugar do original. O dilema especial que a acompanha é o paradoxo do conhecimento e da representação nas artes como descrto por Wesley Trimpi (Muses of One Mind, The Litarary Analysis of Experience and its Continuity, Princeton, NJ: Princeton University Press, 1983, 97-98): "É útil formular o dilema como uma distinção entre a excelência do objeto a ser representado e a precisão com a qual a mente pode conhecer o objeto. [...] A primeira premissa, então, afirma que o valor do conhecimento pode ser mensurado de dois modos: primeiro, com respeito à importância de seu objeto e segundo, com respeito a plenitude e precisão de sua informação sobre o objeto. $\mathrm{O}$ primeiro modo considera o que é conhecido, o segundo como isso é conhecido. A segunda premissa da distinção entre excelência do objeto e precisão do conhecimento afirma simplesmente que esses dois modos de avaliar o conhecimento são inversamente proporcionais um ao outro. Isto é, quanto mais excelente o objeto, menos apreensível e por isso menos exatamente pode ser representado. Por outro lado, quanto mais precisamente o objeto pode ser conhecido e representado, menos removido e por isso menos excepcional ele está apto a ser."

${ }^{6}$ Jacques Rancière, Politik der Bilder [Le destin des images, Paris 2003], Berlin: Diaphanes, 2005, 13; minha tradução K. R
} 
exclusivamente visuais. Nesse sentido, o teatro deve ser entendido como um jogo de operações entre o visível e o audível, entre figuras e palavras, entre imagens e sons. O visível pode existir sem imagens e há imagens que consistem apenas de palavras. Para citar Rancière: "O visível pode ser organizado em tropos significantes, a palavra pode desenvolver uma visualidade que cega"”.

O Teatro Pós-dramático proporciona um desafio específico para as operações entre o visível e o audível, por causa de sua prática de romper modos de similaridade pela desconstrução da ordem do texto dramático clássico (diálogos, continuidade do tempo, enredo e espaço, e a construção de personagens), e sua posição dominante em relação à performance em si. Enquanto o teatro dramático busca representar a realidade pela criação de um mundo ficcional credível que absorve o espectador na lógica do drama, o teatro pós-dramático destrói essa lógica e foca a atenção do espectador na realidade (e materialidade) teatral do que é visível e audível, nos meios específicos que constituem a performance. É a disrupção entre texto e palco que está em jogo aqui. As consequências são formuladas por Hans-Thies Lehmann no seu livro canônico Postdramatisches Theater, que cunhou a noção propriamente dita em $1999 .{ }^{8}$ O foco na realidade física, sensual da experiência espacial e temporal do visual, do acústico e do cinético, vai junto com "a exposição do princípio aplicada ao corpo, gesto e voz que ataca a função de representação da linguagem. Em lugar de uma re-apresentação dos fatos, há uma 'posição' de tons, palavras, frases, sons que são dificilmente controlados por um 'significado' mas, ao contrário, por uma composição cênica, por uma dramaturgia visual, não por uma dramaturgia orientada pelo texto. ${ }^{9}$

No que se segue eu ligarei as afirmações do teatro pós-dramático ao desafio do irrepresentável de Rancière ${ }^{10}$, para pensar a representabilidade das imagens traumáticas no palco por uma modificação de equivalência no sentido em que elas performam

\footnotetext{
${ }^{7}$ Rancière, Politik der Bilder (veja nota 6), 14

${ }^{8}$ Hans-Thies Lehmann, Postdramatisches Theater, Frankfurt a.M.: Verlag der Autoren, 1999.

9 Hans-Thies Lehmann, Postdramatisches Theater. Traduzido e com uma introdução de Karen JürsMunby, Londres e Nova York: Routledge, 2006, 146.

10 Ver Jacques Rancière, "Are some things unrepresentable?" in: The Future of Image, Londres: Verso, 2007, 114: "[...] sob que condições pode ser dito que certos eventos não podem ser representados? Sob que condições pode ser dado a um fenômeno inrepresentável desse tipo um formato conceitual específico? [...] Eu gostaria de introduzir essa questão geral começando de uma inquirição mais estreita que foca na representação como um regime do pensar sobre arte. O que precisamente está sendo dito quando é mantido que certas entidades, eventos ou situações não podem ser representadas por meios artísticos?"
} 
" um jogo de operações que nós chamamos arte"11. Para fazê-lo, é necessário discutir o problema da mimesis que Rancière levanta, na sua investigação, que "foca na representação como um regime da arte"12 Pois é precisamente a mimesis que forma o centro desse regime. Ele entende mimesis como sendo constituída por uma relação entre dois termos: poiesis e aesthesis. A primeira é um modo de fazer, referindo-se a uma certa ordem de ação, a segunda é uma economia de, afetos, referindo-se a uma certa distribuição da percepção cognitiva e sensível. ${ }^{13}$

Elaborarei sobre esses argumentos no contexto da peça Babel de Elfriede Jelinek, encenada por Nicolas Stemann no Wiener Burgtheatre em 19 de março, de 2005. Babel é particularmente interessante no que diz respeito ao texto, bem como, aos acontecimentos do palco, porque ambos dão origem a questões relativas à adequação, à ordem e aos limites dos meios de representação. Na verdade, nós poderíamos argumentar que eles disrompem o relacionamento "clássico" entre mimesis, poiesis e aesthesis. Antes de demonstrar como Stemann lida com a visibilidade do palco ao performar a redistribuição do visível de Julinek, eu resumirei muito brevemente o contexto e as principalis estratégias de texto teatral dela.

\section{Babel de Elfriede Jelinek}

Babel é parte de um 'work in progress' que Elfriede Julinek empreende como uma reação imediata e comenta às representações da mídia aos eventos que aconteceram na sequência do dia 11 de setembro: a guerra do Iraque e a tortura e humilhação de prisioneiros encarcerados em Abu Ghraib e na Baía de Guantanamo. Como Bambiland, a primeira parte desse 'work in progress', encenado por Christoph Schlinges-

\footnotetext{
${ }^{11}$ Ver nota 6.

12 Ranciére, Future of the Image (ver nota 10), 114.

${ }^{13}$ Ranciére, Future of the Image (ver nota 10), 112. A distribuição da percepção cognitiva e sensível está no coração do entendimento de Rancière das implicações políticas da estética. O principal termo que ele desenvolveu nesse ponto é "a distribuição do sensível' (Ver Jacques Rancière, The politics of aesthetics. The Distribution of the Sensible, Londres, Nova York: Continuum, 2004). Nesse contexto, estética emerge como uma prática de dois desdobramentos. De um lado, há uma estética que reside no centro da politíca propriamente dita que funciona como uma delimitação e demarcação de espaço e tempo, do visível e do invisível, da fala e ruído que determina a política como uma forma de experiência política. Por outro lado, há uma outra forma de estética que gera práticas artísticas e políticas como o teatro e a performance. Essas práticas artísticas desafiam a distribuição geral do sensível colocando junto elementos hetereogeneos que provocam um choque ou quebra na percepção, para exibir certa conexão secreta de coisas escondida atrás da realidade do dia a dia. Ver Kati Röttger, "Media/Politics in Performance. Bambiland by Elfriede Jelinek and Christoph Schlingessief", in: Meike Wagner et. al, eds., Beyond the Matrix, Munchen: Epodium, 2008, 337-357.
} 
sief em 2003, Babel visa uma intervenção polêmica no fluxo de informação da mídia global. O principal objetivo de Jelinek é enfrentar o excedente de imagens traumáticas que criaram uma esfera pública de permanente estado de emergência para além do conhecimento, um estado que leva à repressão da história, ao que Roland Barthes chama de uma paralisação mítica do tempo. ${ }^{14}$

Jelinek tende a desconstruir essa estratégia do excedente da mídia. Ela inscreve os ataques terroristas dos fundamentalistas islâmicos, a guerra colonial e as torturas, bem como as representações pictóricas desses eventos, dentro de uma história díspar de tempos, lógicas e espaços.

Primeiro, ela funde fatos da atualidade política com ficção mitológica. Essa estratégia já é aparente no título da peça. O termo hebraico "Babel" se origina do Velho Testamento e significa confusão, mescla, mistura. É o lugar mitológico de Babilónia, mas ao mesmo tempo, é também a cidade situada a oitenta quilômetros ao sul de Bagdá. O locus da trama é, portanto, encenado como um sítio arqueológico de muitas camadas que figurativamente revela e confronta fragmentos de diferentes estórias e de diferentes tempos. Uma importante fonte que inspira o texto é o velho mito grego do sátíro Marsyas. Ele é a vítima da busca de Atena para superar a Górgona Medusa e do desejo de vencer de Apolo. Após ter participado na morte de Medusa, Atena inventa uma flauta para imitar as górgonas, lamentando a morte de Medusa. Porém ela para de tocar a flauta quando Hera e Afrodite riem dela por causa de sua aparente feiura. Ao olhar seu rosto na água ela descobre que, enquanto estava tocando, sua face havia mudado para uma máscara igual à Medusa com bochechas inchadas e olhos esbugalhados. Então ela joga a flauta fora e lança uma maldição sobre o objeto. Marsyas pega a flauta e consegue tocá-la muito bem. Apolo, o rei da lira, fica enciumado da habilidade de Marsyas e o desafia a um concurso de música. Apolo trapaceia, ganha o concurso e tira a pele do sátiro, esfola-o vivo e crava sua pele em uma árvore. Jeliek usa elementos desse mito e os transforma em novas formações discursivas através da fusão dessas imagens míticas de horror com imagens atuais de tortura em Abu Ghraib que foram destribuídas pelos meios de informação. ${ }^{15}$

Embora o texto seja construído em termos de três monólogos, respectivamente chamados “Irm sagt” (12 páginas), "Margit sagt” (35 páginas) e "Peter sagt” (93 páginas), as três vozes falantes são também compostas de um modo polifônico e díspar. A voz de

\footnotetext{
${ }^{14}$ Roland Barthes, Mythologies, Paris: Editions du Seuil, 1957.

${ }^{15}$ Ver também Alexander Jackob and Kati Röttger, "Who owns the images? Image Politics and Media Criticism in Theatre: A separation of powers", in: Image \& Narrative. Online Magazine of the Visual Narrative, Sept. 2007. Sec
} 
Peter entrelaça as posições de Pai, o deus grego Apollo, o Presidente Bush, o mercenário, a figura mitológica de Marsyas, o islamita homem-bomba suicida e os torturados. Princípios ou posições justapostos resultam em uma figura mista: o culpado e a vítima, o oriente e o ocidente, o apolíneo e o dionisíaco, mito e atualidade política. O mesmo acontece com a figura híbrida ou zombi de Margit: aqui a Mãe Ocidental, a deusa Atena, as torturadoras femininas Lynndie, Sabrina e Mergan, a Virgem Maria, a Mãe de Mohammed e a mãe do terrorista mártir emergem. Desse modo, Jelinek de fato coloca em jogo o efeito dissimilar da arte. Através da realização de jogos de palavras, ela cria novas, outras imagens a partir da 'transmissão ao vivo' da mídia eletrônica digital. Ela arrebata o horror da tortura dessas imagens e nos força a vê-las de uma maneira nova, inesperada e incalculável. Um dos muitos exemplos possíveis é o seguinte:

Primeiramente nos espantamos e obtemos o Trauma, então prendemos em nossa garganta, que fica estrangulada, então não podemos nunca mais dormir. E não somos compensados por isso! Talvez tenhamos a corda na garganta e Lynndie a aperte, pois ela acha isto bastante engraçado. ${ }^{16}$

Aqui Jelinek dispara uma cadeia de modificações que dizem respeito às transformações ligadas ao significado comum de trauma com a imagem da soldada americana Lynndie England, que se tornou famosa pela aparição em fotografias tiradas na prisão de Abu Ghraib, nas quais ela é vista posando com prisioneiros torturados, em diferentes situações de humilhação. O jogo de palavras que conecta esses dois assuntos é baseado no verbo "zuzihen" ou "einschnüren", os quais significam "apertar" e ou "estrangular." Combinando essas palavras tanto com "Trauma" quanto com "Hals" (pescoço) ou "Leine" (liderança) e falando sobre "uns" (nós), assim como sobre Lynndie, ela está amarrando a imagem bem conhecida dos prisioneiros aterrorizados pelos cachorros cuja trela Lynndie segura em suas mãos com a "nossa" escopofilia, nosso desejo de olhar para as imagens horríveis, que está escondida atrás da superfície do discurso das imagens traumáticas e simplesmente provoca a sua distribuição. O que Jelinek está realizando aqui, então, é, para usar Rancière, o desenvolvimento de uma prática artística que desafia a distribuição geral do sensível, colocando juntos elementos heterogêneos que provocam um conflito e uma ruptura na percepção, para desvelar algumas conexões secretas de coisas escondidas por trás da realidade cotidiana.

Essa estratégia de dissimilaridade é estruturada por núcleos temáticos que, mais uma vez, misturam os tempos, lógicas e lugares díspares. Um desses núcleos refere-

${ }^{16}$ Elfriede Jelinek, "Babel", in Jelinek, Bambiland, Babel. Zwei Theatertext, Reinbeck bei Hamburg: Rowohlt, 2004, $85-228,182$ 
-se explicitamente à medialidade de olhar e ser olhado, indicada pela palavra Netzhaut (retina). Por outro lado, a palavra está conectada com o repetido assunto da pele Haut (esfolar = copiar), que nós já conhecemos do mito de Marsyas e que está relacionado à Netz digital, à Internet, à "world wide web". Para explicar isto eu cito um fragmento do longo monólogo "Peter sagt" em Babel:

Sie können von mir aus meine Haut von mir trennen, aber nicht diesse Fotos! [...] Schauen Sie sich ruhing das Foto an, damit nehmen Sie mir nichts mehr weg. Da schauen sie mir nichts ab. [...] Und dieses Netz ziechen wir voll, voll mit Bilden, jetzt ein. [...] Fremde Menschen haben mir das angetan, und fremde Menschen schauen sich derzeit mein Bild an, es geht von Hand zu hand, von Auge zu Auge, ob zerschnitten oder nicht, das Auge, nicht das Bild. ${ }^{17}$

A essas múltiplas referências, outra camada é adicionada, a referência ao mito de Édipo. O protagonista que entra aqui não é, contudo, Édipo in persona. Por um lado, é o cenário freudiano da castração que é repetidamente trazido à tona por inúmeras variações de conotação sexual do tema da flauta, simultaneamente introduzido pelo mito de Marsyas ${ }^{18}$ Por outro lado, como um personagem antagonista, é a imagem da faca cortante, que no contexto freudiano aponta para o medo masculino da castração. Essa interpretação psicológica é traduzida a um nível mídia-teórico. A frase "Ja, ich öffne Ihnen jetzt die Augen!” (“Sim, eu abrirei seus olhos, agora!”) ${ }^{19}$ não apenas nos lembra de uma maneira bem drástica a famosa imagem do corte no olho do filme Un chien andalou ${ }^{20}$ de Luis Buñuel e Salvador Dalí; de um modo mais abstrato ela também expressa a separação entre imagens e suas mídias (pele e corpo, foto e aparelho). É uma separação que, reminiscente a Édipo cortando seus olhos quando vem a saber seu terrível destino, está destinada a abrir os olhos do espectador contemporâneo das

\footnotetext{
17 Jelinek, Babel (ver nota 16), 158 e 159 ("Eu não me importo se você separa a minha pele, mas não aquelas fotografias! [...] Você pode olhar para elas se você quiser, mas não as leve embora. [...] E agora nós lançamos na rede, cheio de fotos [...] Pessoas estranhas estão olhando minha foto agora, ela passa de mão a mão, de olho em olho, se é ou não cortado, o olho não a foto." Minha tradução, K.R.)

${ }^{18}$ Por exemplo: "Man sollet seine Scheu vor der Flöte des Menschen haben und statt dessen die FLöte der Fraut in die Hand nehmen, was, die hat keine? Das höre-ich zum ersten Mal. Also, ich habe diesse Flöte einmal geh_ort, als diesse pausbäckige Göttin, Lynndie hie囚 sie, in die Flöte geblasen hat. [...] Lynndie und das letzt Glied, von den sie prompt schwanger geworden ist, auf weia, das hätte ich jezt nicht sagen sollen" (Jelinek, Babel, ver nota 16, 218: "Não se deveria ficar com medo da flauta do ser humano e tomar em vez disso a flauta da mulher, o quê, ela não tem nenhuma? Eu escuto isso pela primeira vez. Ok, eu escutei aquela flauta uma vez, quando essa deusa gorda, Lynndie era seu nome, soprou dentro dela [...] Lynndie e seu último pau que a engravidou, ah eu não deveria ter dito isso" Minha tradução, K.R.)

19 Jelinek, Babel (ver nota 16), 137; minha tradução, K.R.

${ }^{20}$ Ver também Uwe M. Schneede: "Ein andalusicher Hund. Das blinde Sehe als Thema" em Die Geschichte der Kunst im 20. Jahrhundert. Von der Avantgarde bis zur Gegenwart, München: Beck, 2001, 100.
} 
imagens horríveis, a levá-lo ao domínio do conhecimento. Dentro desse núcleo, uma desconstrução mídia-teórica da mitologia está em jogo, uma desconstrução que leva do horror mitológico ao conhecimento analítico.

Um segundo núcleo temático é a desconstrução política da mitologia. Apoiando-se em textos de Giorgio Agamben ${ }^{21}$, Jacques Derrida ${ }^{22}$ e Walter Benjamin ${ }^{23}$, esse núcleo aponta para 'Babel' como um espaço metafórico, multicamadas, num estado de emergência. É o espaço da democracia sem direitos fundamentais ("quando é necessário proteger a democracia não é mais democracia"24), mas também o espaço da Baía de Guantánamo, da guerra, e da mídia. O caso da Baía de Guantanamo, portanto, serve aqui para perguntar sob que condições algumas vidas humanas deixam de ser elegíveis aos básicos, se não universiais, direitos humanos. O governo americano pôde apenas justificar o fato de que um número de detidos em Guantanamo não foi sequer julgado apenas pela publicação, na época, de novos regulamentos. Jelinek liga esse caso a questões básicas relativas à democracia, e com a necessidade de repensar o que Judith Butler chamou de "a relação entre soberania e lei: "Para saber o que produz a extensão de soberania no campo da governamentalidade, primeiro nós devemos discernir os meios pelos quais o estado suspende a lei e os tipos de justificativas que eles oferecem para essa suspensão" ${ }^{25}$ É o espaço onde valores democráticos de lei, direito e dignidade humana (por isso, questões de ética) estão fora de ordem. O espaço multicamadas é também o espaço do texto Babel em si, "Moralkunstwerk"26 de Jelinek (obra de arte da moralidade - o termo alemão parece poder traduzir-se por «obra de arte moral»), que

\footnotetext{
${ }^{21}$ Eu estou me referindo a versão alemã: Giorgio Agamben, Homo Sacer. Die Souveräniät der Macht und das nackte Leben, Frankfurt a.M: Suhrkamp, 2002. Agamben introduz a noção de um homo sacer remetendo-se à lei romana arcaica na qual a vida nua foi incarnada pela figura do homo sacer: era-lhe permitido ser morto, mas não sacrificado. Portanto ele era ao mesmo tempo tocável e intocável o que tornou sua morte bastante sem sentido. Ele marca a fronteira entre a vida nua e a legal, e caracteriza a soberania propriamente dita. Desenvolvendo mais adiante o conceito de soberania, Agamben profere uma análise dos campos de concentração como um estado de emergência e "nomos de modernidade", onde direitos e ações legais, regra e exceção, vida e morte tornam-se inseparáveis.

22 Jaccques Derrida, Rogues. Two Essays on Reason, Stanford, CA: Stanford University Press, 2005. Derrida está lidando aqui com a questão das interenções legítimas no Iraque e em qualquer outro lugar, o status do vadio e as condições de democracia.

${ }^{23}$ Wlater Benjamin, Zur Kritik der Gewalt und andere Aufätze, Frankfurt a.M: Suhrkamp, 1999.

${ }^{24}$ Jelinek, Babel (ver nota 16), 2010: minha tradução, K.R.

25 Judith Butler, "Indefinite Detention", in Butler, Precarious Life. The Powers of Mourning and Violence, London, New York: Verso, 2004 50-100, 56.

${ }^{26}$ Isso pode ser entendido como uma sugestão à famosa reivindicação de Schiller por um "Theater als moralische Anstalt", que retoma mesmo as reivindicações éticas de Aristóteles definidas para o efeito da tragédia.
} 
está buscando pela moral como um personagem principal: "Du sollst doch jetzt eingeführt werden! Ich brauch dich doch, du bist schließlich die Hauptfigur"27

A resposta para "por favor repita a pergunta" que Jelinek dá em seu texto consiste em uma reflexão perfomativa sobre a adequação dos meios teatrais em um modo pós-dramático, para reivindicar justiça e moralidade. Para fazer isso, ela conecta seu texto às reflexões de Benjamin sobre linguagem no texto Kritik der Gewalt, para desconstruir a ideia dele de elaborar uma mitologia política. Congregando a ideia de auto-reflexividade da obra de arte com os núcleos mídia-teórico e político mencionados acima, ela redefine a adequação do teatro político de hoje.

Nas palavras de Rancière pode ser dito que Jelinek gera uma reflexão sobre a adequação, a ordem e os limites dos meios representacionais. Em jogo aqui está a relação entre ética (responsabilidade) por um lado, e mimesis, poiesis e aesthisis (a ordem do visível e do dizível), por outro. A investigação de Jelinek dessa relação volta às leis da tragédia definidas por Aristóteles. É uma questão que desafia o teatro em sua função contemporânea como uma obra de arte de moralidade. Em minha formulação dessa questão: $\mathrm{E}$ os efeitos da tragédia aristotélica (o que se poderia chamar de uma obra de arte moral per se), de elos (piedade), e phobos (medo), e o efeito de catharsis em um mundo que está paralisado pelo olhar de Medusa?

Seguindo Rancière, o teatro é o terreno preferido da representação. ${ }^{28} \mathrm{O}$ teatro de que ele está falando é a tragédia porque ela lida com um certo ajustamento da realidade que toma a forma de uma dupla acomodação:

\begin{abstract}
Por um lado, as entidades da representação são entidades ficcionais, isentas de qualquer julgamento de existência, e assim libertas da questão platônica sobre sua consistência ontológica e exemplaridade ética. Mas, os seres ficcionais são no entanto seres de semelhança, seres cujo sentimentos e ações devem ser compartilhados e apreciados. A "invenção das ações" é tanto uma fronteira quanto uma passagem entre duas coisas: os eventos, simultaneamente possíveis e incríveis, que a tragédia liga; e as volições e os conflitos da vontade partilháveis e reconhecíveis que ela oferece ao espectador. ${ }^{29}$
\end{abstract}

Essa especial passagem e fronteira entre palco e auditório, esta vinda à presença do mundo ficcional apoia-se numa dupla retenção: "A retenção do visível sob o dizível e dos significados e efeitos sob o poder da ação - uma ação cuja realidade é idêntica

\footnotetext{
${ }^{27}$ Jelinek, Babel, 207, 208 ("Moral, moral, onde está o seu ferrão? Eu não a vejo por agora, aonde você foi para minha obra de arte? Eu preciso de você! Você é meu principal personagem" Minha tradução, K.R)

${ }^{28}$ Rancière, Future of the Image (ver nota 9), 116

${ }^{29}$ Rancière, Future of the Image (ver nota 10), 116
} 
a sua irrealidade"30. Rancière chama a esse o regime de subdeterminação porque ele enfraquece o visível e, portanto, acentua o ajuste ético e político da lógica do saber, agir e sofrer. Na Poética de Aristótoles, o Édipo Rei de Sófocles é o modelo do uso correto da peripeteia e reconhecimento: a interação certa entre o pathos ético do conhecimento (reconhecimento) e um pathos do afeto que é o sofrimento. Somente porque Édipo cega-se para alcançar reconhecimento e conhecimento (que é mimesis, poiesis e aesthesis) é que ele finalmente torna-se capaz de 'ver'. Bem no momento do reconhecimento dele - o chamado climax da tragédia - o espectador reconhece a sua cegueira, a máscara sem olhos sangrenta de olhos cortados é colocada bem em frente a si em prol da catarse e da purificação moral.

Enquanto Sófocles, de acordo com Aristóteles, transferiu o pathos ético do conhecimento para uma relação estável entre poesis (um arranjo autônomo de ações) e aesthesis (a entrada em operação dos afetos) ${ }^{31}$, Jelinek desarranja essa ordem de representação. Ela descontrói as normas de Aristóteles da ação representativa pela não-figuração (não há mais personagens, apenas fluxos monológicos de textos) e pelo poder performativo de refletir sobre o fazer e transformar de seu trabalho artístico. Ela usa o bisturi para cortar através da identificação, através da relação estável entre poiesis e aesthesis, através da catharsis, através das leis de representação, para expor cada órgão da obra de arte moral como uma parte crítica da história ocidental da representação ainda em curso. O texto de Babel indica isso do seguinte modo:

Das ist mein Thema: Moral! Moral Sour! [...] Die Moral sollte auch selber die Hauptrolle übernehmen, denke ich. Wenn es schon von ihr handelt, dann soll sie auch selber spielen, finde ich [...] Aber ich lasse nicht davon $\mathrm{ab}$, schon wieder ganz anders zu denken als sie. Ich denke jetzt sogar volkommen umgekehrt selber ihren Preis. Ich fühle direkt, ich fühle alle Arten von Grausamkeit direkt am eigenen Leib, ohne sie je spüren zu müssen. Já, das geht wirklich ins Körperlich hinein, echt, aber zum Glück doch nicht echt. Aber wenn Sie sich unbedingt diessen mit derm Messer auf dem Schlachtfeld Geköpften, eigentlich Gesägten, Gesäbelten, anschauen müssen, in solchen Massen, die sie darstellen und sind, wenn Sie ihn unberdingt in solchen Mengen anschauen müssen, dann ist es kein Wunder, da囚 der Server crasht, bitte dann können Sie ihn halt nicht sehen. ${ }^{32}$

\footnotetext{
${ }^{30}$ Rancière, Future of the Image (ver nota 10), 116

${ }^{31}$ Ranciére, Future of the Image (ver nota 10), 115.

32 Jelinek, Babel, 139, 141, 142 ("Essa é a minha questão: a moral! [...] A moral deve assumir o papel principal. Se já se trata da moral, ela deve agir por si mesma, eu acho. [...] Eu não paro para pensar diferentemente. [...] Eu até acho o contrário. [...] Ainda que o diretor tenha pensado sobre isso, mas a moral não negocia, ela determina seu preço por si só. Eu sinto diretamente, eu sinto todos os tipos de crueldades diretamente, eu as estou experenciando sozinho sem ser forçado a senti-las. É horrível ser forçado a imaginar o horror. Sim, aquilo atinge o corpo, realmente, mas felizmente não realmente. [...] Mas se você tem que ver este corpo, esta faca sobre o campo de batalha corpo,
} 
Essas palavras revelam a poética pós-dramática de Jelinek como o que eu chamaria de poética pós-traumática. Ela radicalmente assume a retenção do visível sob o dizível, mas nega a retenção de significados e efeitos sob o poder de ação. A ordem do mimético, a identidade da realidade com a irrealidade é deslocada. Ela torna-se o meio das mídias propriamente ditas: das notícias, tele-tecno-iconicidade, web-espetacularidade que geralmente assegura e determina o espaço público, o discurso social e as produções de imagem social. Ao invés de compactuar com isso, Jelinek decide escoIher pela heterogeneidade radical e necessária da herança que diz respeito à mitologia, história e tragédia; essa herança pode somente ser una dividindo-se, despedaçando-se, diferindo-se, falando ao mesmo tempo - e em vozes diferentes. Em outras palavras, seu empreendimento pós-traumático consiste em performar eventos traumáticos de tortura, trabalhando através dos modos miméticos de representação, despedaçando-os, adaptando a separação de olho e imagem, imagem e mídia, corpo e pele, bem como o efeito (moral) e o afeto da obra de arte sobre o espectador encarnado.

Conectando os efeitos morais das representações traumáticas à violência (relacionada também ao corpo executivo do estado ${ }^{33}$ ) e à justiça (ou injustiça), Jelinek segue Derrida, o qual pode ser chamado de orador-fantasma da peça dela. No seu famoso ensaio Specters of Marx ele refere-se a estar com espectros como uma atitude que também pode ser chamado de uma política da memória e das gerações, porque é sobre os outros e sobre a justiça: "Nehuma justiça [...] parece possível ou pensável sem o princípio de alguma responsabilidade, para além de todo o presente vivo, dentro daquilo de desjunta o presente vivo, perante os fantasmas daqueles que ainda não nasceram ou que já estão mortos, sejam eles as vítimas da guerra, de violência política ou de outra espécie, de extermínios nacionalistas, racistas, colonialistas, sexistas, ou de outros tipos"34 O que Jelinek em sua obra de arte moral pós-traumática está convocando é a justiça e a responsabilidade para além do presente vivo, considerando, pelo trabalho através do mito, a historicidade descontínua de atos traumáticos reprimidos. Portanto, ela descontrói as 'imagens traumáticas' específicas das torturas

\footnotetext{
sim, por exemplo, o corpo por uma só mão decapitado, embora talvez não decapitado com as próprias mãos. Se você tem que ver este corpo em tais massas, [...] em tais quantidades, então não é de admirar que o servidor falhe, por favor, então você simplesmente não pode vê-lo" Minha tradução, K. R)

33 'Gewalt' significa 'violência', mas o corpo executivo do estado é também chamado 'Staatsgewalt'

${ }^{34}$ Jacques Derrida, Specters of Marx. The State of the Debt, the Work of Mourning, and the New International. Traduzido por Peggy Kamuf, com uma introdução de Bernd Magnus e Stephan Cullenberg, Nova York, Londres: Routledge, 1994, 19.
} 
para fazê-las evidentes como uma parte concreta de nossa atual situação histórica, arrancando-as do eterno 'main-stream' da indústria do entretenimento, que naturaliza horripilantes eventos de injustiça.

\section{A Encenação de Babel de Nikolas Stemann}

Na transposição das poéticas pós-dramática e pós-traumática de Jelinek para o palco do teatro, Nikolaus Stemann foi confrontado com, pelo menos, três problemas: a visibilidade explícita do palco, a não-figuratividade dos modos representacionais no texto e o excesso de representação pictórica do trauma na mídia. Eu desejo argumentar que ele decidiu por uma interpretação performativa que transforma as próprias coisas que interpreta.

A performance começa com uma recusa radical do domínio visual. Ao público é negada qualquer visão do palco do teatro. A única coisa que nós vemos é uma cortina vermelha fechada. Nesse ínterim, o texto está onipresente no plano auditivo pois está sendo falado por uma voz masculina via um altofalante. A primeira parte do último monólogo, "Peter says", é ouvida, a qual anuncia, no final da poética pós-traumática de Jelinek, a herança heterogênea da genealogia da representação teatral. Após quinze minutos de escuta, nós, de repente, vemos um pequeno holofote na parte inferior da cortina. Um minúsculo sapo verde de fantoche aparece, depois outro. Eles performam os "free radicals"; vírus que estão atacando o sistema imunológico da rede - e portanto da democracia ocidental. Eles estão repetindo partes do monólogo que nós acabamos de ouvir, da voz de "Peter" que tivera sido transmitida por um altofalante, agora transformada em um diálogo e, um pouco mais tarde, em um coro de minúsculos sapos verdes. Quando esses 'terroristas' têm que passar pela tortura - a primeira culminação de violência nessa imagem ambivalente - a cena muda: Margit aparece, juntamente com os manipuladores dos fantoches. Eles discutem suas responsabilidades no ato de tortura que eles performaram antes de manipular os sapos. Essa é uma exibição do anti-mimético, do ator épico e do teatro de Brecht. Ao mesmo tempo, ilustra a qualidade iconoclástica da cena.

O que se segue é um crescendo lento de efeitos visuais: a imagem conquista o palco. A cena começa com uma configuração clássica de um teatro ilusionista burguês: o drama familiar. Os atores Peter and Margit transformam-se em pai e mãe cercados por suas crianças. A cortina abre, e um cenário burguês é revelado, o ícone 
cristão da cruz funcionando como um ponto de fuga de um 'tableau' cuidadosamente preparado. Essa configuração teatral mimética clássica então mostra-se como tendo similaridades com o cenário de uma novela de TV estrelando os Jelineks, acompanhada pela típica trilha de riso. Então segue-se outra mudança, mas agora no mesmo ambiente. Apenas o ícone muda, juntamente com a luz: uma troca simples da cruz por um quadro de Bin Laden faz o espectador testemunhar uma guerra notável de imagens. Esse choque introduz uma série de múltiplas camadas de outros conflitos. Após o prólogo e depois da exposição de diversas formas dramáticas de representação, nós entramos no domínio do pós-dramático. O mote agora tornou-se 'encenar a tela'. Os conflitos deslocam-se para um nível conceitual: entre, por um lado, a estética da performance das vídeo instalações que fragmentam o corpo, e, por outro, o trivial entretenimento-showbiz da TV. Essa justaposição é mais uma vez sustentada por um ambiente conflitante: a batalha entre o significado estético do visível e do audível, visualização e musicalização: os princípios apolíneo e dionisíaco que foram definidos por Nietzsche em seu A Origem da Tragédia. O princípio racional, o deus e herói da lógica e da imaginação está competindo contra a figura mitológica, sangrenta, orgiástica, letal, inclinada à música, de Marsyas. Para o fim da performance, essas imagens culminantes gradualmente se misturam em uma imagem contraditória. Nesse ponto culminate de efeitos visuais e sonoros, Stemann pega sua faca teatral: ele introduz o tema de Édipo. Mas, aqui novamente, não é o Édipo in persona que aparece: os espectadores não assistem aos sangrentos olhos cegados no fim; ao invés disso, os próprios espectadores são cegados. Uma inundação de duros flashes de luz do palco diretamente nos olhos dos espectadores. A 'faca' de Stemann corta pelo meio do palco e dos olhos dos observadores. Então nós, os observadores, não sentimos com o Édipo cego (catártico), nós performamos o Édipo cego. Nós não imaginamos a dor, nós sentimos dor em nossos olhos, sem estarmos aptos a olhar. Ao final do espetáculo, os espectadores não somente reuniram conhecimento sobre a história da representação para identificar formas de ver, saber e falar historicamente constituídas; eles são até mesmo forçados a experienciar a cegueira como uuma precondição edipiana de conhecimento - uma precondição para superar a mitologia e portanto a abundância de espetaculares imagens traumáticas na mídia de massa.

Eu desejo fechar referindo-me à noção de Judith Butler do 'espectador global', refletindo sobre os eventos que foram contados sobre os horrores da guerra pela mídia 
de massa, para deixar claro o quão longe Jelinek e Stemann tentaram intervir nessa mesma precária esfera pública global que foi criada após 11 de setembro:

Talvez a questão não possa ser escutada de todo, mas eu ainda gostaria de perguntar: podemos nós achar outro significado, e outra possibilidade, para o descentramento da narrativa na primeira pessoa dentro do quadro global? Eu não quero dizer que a história que começa com 11 de setembro não deva ser contada. Essas histórias têm de ser contadas, e elas estão sendo contadas, a despeito do enorme trauma que mina a capacidade narrativa nessas instâncias. Mas, se nós chegarmos a nos entender como agentes globais, e a atuar dentro de um campo historicamente estabelecido, e um que tenha outras ações em jogo, nós necessitaremos emergir da perspectiva narrativa do militarismo dos EUA e, por assim dizer, suas estruturas defensivas, para considerar as formas nas quais nossas vidas estão profundamente implicadas nas vidas de outros. ${ }^{35}$

Eu acho que Babel é uma resposta possível para essa questão altamente ética, porém será necessário mais.

35 Judith Butler, "Explanation and Exoneration, or what we can hear", in: Butler, Precarious Life (ver nota 25), 2004, $1-18,7$. 